Investigations

\title{
Examination of Overall Equipment Effectiveness (OEE) in Term of Maynard's Operation Sequence Technique (MOST)
}

\author{
${ }^{1}$ Puvanasvaran A. Perumal, ${ }^{2}$ Ito Teruaki, ${ }^{1}$ Teoh Yong Siang and ${ }^{1}$ Yoong Sai Sieng \\ ${ }^{I}$ Faculty of Manufacturing Engineering, \\ Universiti Teknikal Malaysia Melaka, Durian Tunggal, 76100 Melaka, Malaysia \\ ${ }^{2}$ Faculty and School of Engineering, \\ The University of Tokushima, Minami Jousanjima-cho, Tokushima, Japan
}

\author{
Article history \\ Received: 29-09-2016 \\ Revised: $17-10-2016$ \\ Accepted: 05-11-2016 \\ Corresponding Author: \\ Puvanasvaran A. Perumal \\ Faculty of Manufacturing \\ Engineering, Universiti \\ Teknikal Malaysia Melaka, \\ Durian Tunggal, 76100 \\ Melaka, Malaysia \\ Email: punesh@utem.edu.my
}

\begin{abstract}
It is a common practice to quantify any process or entire production line in manufacturing industry especially to measure three main losses named time losses, performance losses and quality defect exist in production. Overall Equipment Effectiveness (OEE) fulfils the requirement by providing the measure of equipment via single measure which is monitored from time to time by responsible personnel so that corresponding optimization or Kaizen could be done. However, there are many lean wastes which could be 'invisible' or tolerated under the conventional definition of OEE. The hidden waste includes unnecessary production which was classified as operating time and the underestimated effect of excessive transportation or setup time. These could be minimized and sometimes avoidable via work measurement, method study and study of the work, which are under the study of Maynard's Operation Sequence Technique (MOST). This paper intends to examine and quantify the hidden lean waste in OEE from the perspective of method and work of an operation with the integration of MOST study. Operations are analyzed in every single step and broken down into details of activities, which are then re-designed for minimal non-value added activity in operation based on the standard allowable. The OEE data after the study of work is computed and compared with the OEE before the MOST study. The comparison shows the improvement in term of OEE after the MOST study and this implies that the hidden waste inside OEE definition could be tracked out for a better effectiveness. Any reduction in the non-value added activities or downtime ensure larger room for more value added activities or uptime and therefore the availability of production. It is expected to provide a new insight in implementing OEE at a different way and stay beware of the assumptions in OEE to avoid any hidden waste.
\end{abstract}

Keywords: Overall Equipment Efficiency (OEE), Maynard's Operation Sequence Technique (MOST), Study of Work, Work Measurement, Hidden Waste

\section{Introduction}

Overall Equipment Effectiveness (OEE) has been implemented by most of the companies which wish to keep their equipment running at all time, not slower than the ideal speed and always producing products in good quality. It measures the effectiveness of any production equipment in a factory in terms of availability, performance and quality perspective which quantifies any time losses, speed losses and quality losses respectively.

However, keep the equipment running all the time does not necessarily mean that the company is effectively utilizing the equipment. This is because the operation done on the products or Work In Progress (WIP) is sometimes non-value added or deems redundant. In other words, the operation of the equipment could be adding the features that are not 
essential or avoidable via more effective operation. Due to the fact that production is not perfect in actual, operation of an equipment is sometimes the rework or additional process which should be examined, streamlined or optimized from time to time. Planning factor which is defined as the ratio of total production planned over the maximum capability, for instance, has been demonstrated about its importance to be incorporated in measurement of OEE to prevent any additional operation (Puvanasvaran et al., 2014). This is because sub-utilization of equipment is sometimes due to inefficient production planning and therefore the inability of equipment to meet market demand via minimal operation will further contribute to additional operation. In addition to that, the availability ratio of OEE measures only the ratio of total operating time over the whole production time and emphasizes only on the control and monitoring of time losses. The aforementioned rework or additional operation is treated as the operating time as per definition of availability even though they are not necessary or essential.

Besides that, man power is crucial for the industry with semi-automated or manually operated production line to operate most of the equipment or machines. Due to the absence of Standard Operation Procedure (SOP) or fatigue of employee, some excessive transportation exists during set up processes. This is aligning to the fact that unproductive movement exists on daily task (Abu Talib and Daiyanni, 2010). Consequently, planned downtime will increase due to the excessive transportation and adversely affect the availability of equipment itself.

In addition to the setup process, the semi-automated process requires assistant of operator also during the running of equipment. The low efficiency of operator due to unnecessary motion will contribute to delay or slow performance of equipment. From the perspective of Lean, it is considered as waste in the category of waiting, movement and unnecessary processing. All these should be quantified in the performance losses and monitored from time to time to yield a more effective process at a faster pace.

Nevertheless, it is recommendable to refer to historical availability of equipment in future production planning (Puvanasvaran et al., 2013). This is similar to the monitoring purpose of OEE to promote Kaizen activities and hence improvement in effectiveness of process for more market demand. In order to ensure the reliability of the measurement, accurate definition of the availability should be established before collecting the data and making any change on the production line.

Work measurement, method study and study of work should be carried out onto the production in order to track out any process to be optimized or could be further streamlined. This is important to be not affected by the definition of availability in conventional OEE. After the optimization and streamline of unnecessary operation in the process, data is collected for the computation of OEE data. It is recommended to consider the unnecessary process time as the time loss and then transform it into external setup via method study if possible. Performance measurement is important so that performance gaps between current stage and desired performance could be reduced (Samad et al., 2012).

\section{Literature Review}

\section{Hidden Wastes in OEE}

Performance ratio in OEE measures only the deviation of the particular operation from its ideal time. Ideal performance has been defined as the shorter duration elapsed from the moment of equipment starts running and yields maximum amount of output. As such, speed losses occur when equipment is running below designated speed (Benjamin et al., 2015). Due to the fact that ideal time of an operation is difficult to be defined even though based on historical data, performance losses are normally not the focal point or area of improvement by most of the companies. This is because the running time of equipment is always confused with the nonperforming start period which increases with number of changeover and setup. Non-performing start period is the time duration an equipment takes to reach its operating speed (Zeller, 2014). In other words, alternate operation or frequent changeover contributes not only lower availability but also the extended start period which is neglected as normal planned downtime.

In addition, frequent changeover or setup indicates that the time consumed in searching for tools, shortage of material or inadequate verification will lead to waiting or idle between processes which are not quantified in OEE measure. This is because most of the time planned downtime for setup had been fixed by companies for the operator to setup the equipment. All these waiting time or idle activities are treated as part of the standard operation procedures by management due to the non-understanding on process or sometimes operators tend to over-estimate the process time to release time pressure.

Besides that, the process which is carried out by single operator or single process broken down into more than one processes can actually be combined, reduced and simplified using two operators (Adanna and Shantharam, 2013). The possibility of process 
improvement is usually less because the work study is not clear under OEE approach which mentions only the performance in respect to ideal time. Activities should be categorized not only into external and internal type, but also into value-added, non-value added as well as required but non-value added. It has been presented in the system of Single Minutes Exchange of Dies (SMED) to Eliminate the unwanted, Combine, Reduce and Simplify (ECRS) those required but non-value added activities and reduce or rearrange the non-value added like extra turns of bolts during the setup process.

\section{Maynard's Operation Sequence Study (MOST)}

Maynard's Operation Sequence Technique (MOST) is the most suitable tool to be implemented to consider the work movement, method study or study of work. It concentrates on the movement of people and the stuffs that relate in workstation, which will be further analyzed to get the normal time for the particular operation as the work measurement. In the pursuit of the normal time of each activity, many nonvalue added activities in any particular operation and sub-operation could be easily tracked out by using the technique to yield as short standard time as possible. In other words, the Basic MOST analysis is a complete study of an operation or a sub-operation which a worker should perform an activity within a standard time which is between $20 \mathrm{sec}$ to $2 \mathrm{~min}$ (Kjell and Maynard, 2001). It analyzes the movement and gets the normal time for all the activities. These sub-activities are determined in sequence model which includes the parameter that recognized in a reasonable sequence. There are three activities of sequences need in MOST for describing manual work:

- General Move Sequences (GMS) is a sequence used to describe a free movement that related to space for object through the air
- Controlled Move Sequences (CMS) is a sequence used to describe the movement of an object when it remains in contact with a surface or it is attached to another object during the movement

- Tool Use Sequence (TUS) is a sequence used to describe the use of common hand tools. However, the sequence covers the use of hand tools such as writing, fastening or loosening, cleaning and gauging

In addition to that, the sequence model defines the actions that always take place in direct order when the man or object is being moved. The MOST common scale index numbers are $0,1,3,6,10,16,24,32,42$ and 54. From that, the index based on the descriptions of work done can detect the suitable value of the scale. The sequence model is simply adding all the index values and multiplying by 10 to get the TMU for the activities and further multiplied by 0.036 to convert them into time unit of second. It is illustrated from the example of the standard time for sub activities A270B0G0 A0B0P0A270:

$$
\begin{aligned}
& (270+0+0+270)^{*} 10=5400 \mathrm{TMU}, \\
& 5400 \mathrm{TMU}^{*} 0.036 \mathrm{sec}=194.4 \mathrm{sec}
\end{aligned}
$$

Any unproductive labor movement could be one of the inconsistent operations which further leads to variation in cycle time (Lee et al., 2013). This is the reason MOST should be incorporated with the OEE implementation to highlight the portion which draws down the availability and sometime performance of equipment.

Table 1 shows the sequence model and parameters based on the Basic MOST system (Kjell and Maynard, 2001). In addition, the use of brain also describes a mental process as tool use. The summary of sequence model and parameter based on the different activities involved in Basic MOST is as below:

Table 1. The sequence model and corresponding parameters in Basic MOST system (Kjell, 2003)

\begin{tabular}{lll}
\hline Activity & Sequence model & Parameters \\
\hline General move & ABG ABP A & A: Action distance \\
& & B: Body Motion \\
& G: Gain Control \\
P: Placement & M: Move Controlled \\
Control move & & X: Process Time \\
& ABG MXI A & I: Align \\
Tool use & & F: Fasten \\
& ABG ABP ABP A & L: Loosen \\
& & C: Cut \\
& & S: Surface \\
& M: Measure \\
& & R: Record \\
\end{tabular}




\section{Methodology}

A selected wire bond process in a semi-conductor company is studied and quantified in term of OEE as per traditional approach. In doing that, time study and site observation are carried out to acquire essential data. OEE quantification is done after that to mark the initial status before any improvement via MOST approach. In addition to that, observation of the process and work study are carried out at the same time. The work study is useful in order to re-design the wire bond process if necessary so that the equipment could be utilized optimally or at a higher effectiveness. Once the MOST study is carried out and the improvement is implemented, the process is quantified again using OEE to evaluate the effectiveness of equipment. Comparison is then made between the OEE value before and after the MOST to know more about the hidden wastes.

Important part in this study is the site observations which are carried out repetitively throughout the operation, for several cycles, to verify if the actual flow is in accordance to the Standard Operation Procedure (SOP). Besides, time data is also collected for a few months using stopwatch. The advantage of performing time study using stopwatch is that the time data could be taken as many times as it is required. Its snap back mode also enables the observer to record any incidence occurs during the time study such as unnecessary processing or unproductive motion which could possibly be eliminated without affecting the quality of the wire bond. On the other hand, real time monitoring system is used to gather the time data which could not be taken manually like running time of wire bond equipment. The time data collected is shown in Table 2.

The time data as shown in Table 2 is the usual data to be used for OEE quantification like the computation of availability. It is difficult to tell from the data in Table 2 if the process is in an effective way since the details of each activity are not shown. The activity time is tabulated in lump sum manner. It is clear that unproductive labor movement especially during setup process is not examined via the measurement of OEE.

\section{Results}

The Basic MOST is conducted to evaluate the parameter and assign index value for all sub operations involved, which are then summed up to obtain the total normal time. Appendix A shows the mechanism of how Basic MOST finds and minimizes the non-value added movement by using the parameter sequence model on wire bond workstation. The wire bonding process is broken down into details like the number of steps taken from one location to another during setup and also the sequence order of the motion done to take a tool.

It is noticeable that the total time elapsed in actual which is obtained from time study and shown in Table 2, is higher than that obtained from the analysis or redesign of the process using MOST approach as shown in Appendix A.

Setup time before the MOST study is $59.097 \mathrm{~min}$ in actual, which has been reduced to 28350 TMU or 17.01 min after the elimination and minimization of non-value added activities via MOST study. This has yielded the optimization time of around $42.093 \mathrm{~min}$ or about $71.23 \%$ of improvement.

Reduction of movement such as the movement of employee and distance between workstations can lead to drastic reduction in non-value added activities. The improvement has considered the arrangement of material and another process and the use of tools as well.

From the perspective of OEE, the setup time is categorized as the planned downtime since it is required by each processing from the beginning. Lower downtime from the MOST study means larger portion of uptime or operating time is possible for the wire bond machine and also the availability. Prior to the quantification of the aforementioned optimization, it is essential to exclude those activities in the MOST study which could be performed concurrently with the running of wire bond machine, i.e., external setup after the machine starts. Total time elapsed on external setup after machine running is $1990 \mathrm{TMU}$, which equals to $1.19 \mathrm{~min}$.

Table 2. The cycle time of each step in the wire bond process obtained from time study

\begin{tabular}{|c|c|c|c|}
\hline \multirow[b]{2}{*}{ No } & \multirow[b]{2}{*}{ Operation/activities } & \multicolumn{2}{|l|}{ Cycle time } \\
\hline & & Second & Minute \\
\hline 1 & Loading new lot into machine & 34.02 & 0.567 \\
\hline 2 & Machine set up and running & 34.00 & 0.567 \\
\hline 3 & Wire bond running time & 3378.00 & 56.300 \\
\hline 4 & RTI (300 units per magazine) & 0.01 & 0.002 \\
\hline 5 & Unload lot from machine & 24.42 & 0.407 \\
\hline 6 & Fill in lot traveler & 7.80 & 0.130 \\
\hline 7 & Key in MES & 53.76 & 0.896 \\
\hline 8 & Send lot & 13.68 & 0.228 \\
\hline \multirow[t]{2}{*}{ Total } & & $59.093 \mathrm{~min}$ & \\
\hline & & $0.9849 \mathrm{~h}$ & \\
\hline
\end{tabular}


The planned downtime is drastically reduced to 15.81 min after deducting the 1.19 min of external setup in Appendix A. It marks a $73 \%$ of improvement from 59 min before the MOST study and should be incorporated in the OEE measurement as well. Comparison of availability ratio before and after the MOST study is computed as below:

Availability ratio before MOST $=$

(Scheduled Production time-unplanned

Downtime)/Scheduled Production Time

$=(960,120$ and $59.097 \mathrm{~min}) / 960 \mathrm{~min}^{*} 100 \%$

$=81.34 \%$

Availability ratio after $\mathrm{MOST}=$

(Scheduled Production time-unplanned

Downtime)/Scheduled Production Time

$=(960,120$ and $15.81 \mathrm{~min}) /(960 \mathrm{~min}) * 100 \%$

$=85.85 \%$.

The availability had merely improved from $81.34 \%$ before MOST study to $85.85 \%$ after the MOST study. The $4.5 \%$ of improvement is considerably small as compared with the drastic change in setup time of around $73 \%$. In addition, the change in availability ratio will be further diluted or 'unseen' in the measure of OEE. This can be seen by incorporating both performance ratio and quality ratio before and after the MOST study.

Computation of both performance and availability ratio will remain the same as per data from observation and time study since the quality and the performance of the wire bond machine or speed of process are not improved via the MOST study in this study. Their calculations are as below:

$$
\begin{aligned}
& \text { Performance ratio }=\text { Ideal cycle } \\
& \text { time } /(\text { Operating time/Total pieces }) \\
& =0.01 /(122067 / 6,000,800)=49.16 \% \\
& \text { Quality ratio }=(\text { Total production-number of } \\
& \text { defect in pieces }) / \text { Total Production } \\
& =(6,000,800-4800) / 6,000,800=99.92 \%
\end{aligned}
$$

Multiplication of these three ratios enables the comparison of both OEEs as shown below:

$$
\begin{aligned}
& \text { OEE before MOST study } \\
& =\text { Availability ratio * Performance ratio * } \\
& \text { Quality ratio }
\end{aligned}
$$

$$
=81.34 \% * 49.16 \% * 99.92 \%=39.95 \%
$$

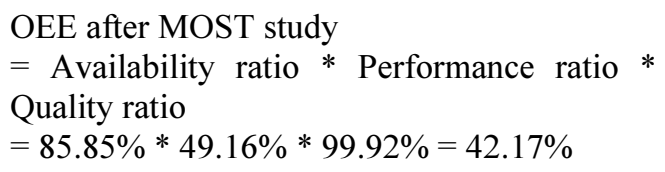

It is clear that drastic improvement in setup time of around $73 \%$ could only lead to merely $2.22 \%$ of improvement in OEE measure. The finding here is not talking about the lessened importance of setup or loading time in the measure of OEE, but it highlights the situation where the OEE itself has been tolerating the lengthy workflow or incorrect working procedure at most of the time.

The suboptimal workflow could be the hidden waste of OEE. This is because the only focus of OEE is to keep the equipment running whenever the focus is on availability. This is not always right because some of the activities could be omitted and eliminated without affecting the quality of product or life-cycle of equipment itself. In other words, when the management team has been informed with a single value of OEE, it is hard for them to immediately track out the hidden waste exist in the setup time, which is around $73 \%$ of redundant sub-operation in this case. In order to make clear of the aforementioned hidden wastes, it is necessary to list down some of the identified problems and lean waste as in Table 3 . They are part of the reason to implement the MOST study and optimize the setup process as shown in Appendix A.

Two problems which adversely affect the uptime of wire bond machine are the waiting time and lengthy loading or setup time in the wire bond process. These are invisible in OEE measures if management team only compares the OEE value from time to time without examining the work method. These problems could actually be reduced by providing a guidance for the operator especially during setup, loading and unloading of product. The unavoidable motion of operator is studied under MOST and a guidance in term of TMU or limit of time should be suggested. The limit of time here is suggested based on the distance between operator and working place, use of tool and the space and therefore should be deemed reasonable. Employee should perform those operations without exceeding the limit of time and therefore eliminate the unnecessary workflow, operation and transportation.

Table 3. Summary of the problems and lean wastes identified in Wire Bonding process

\begin{tabular}{lll}
\hline Problem & Lean waste and description & Root cause \\
\hline Lot sent is not per scheduled time & Waiting for lot from its supplier process, & Scheduling problem. \\
$\begin{array}{l}\text { Machine is not available } \\
\text { Lengthy loading time. }\end{array}$ & die attach (Waiting) & Lack of standard operational procedure. \\
Additional alignment is required. & Finding of new available machine (Motion) & Loading of new lot. \\
\hline
\end{tabular}


In addition to that, the guidance is useful to promote a more efficient unloading way of lot from wire bond machine and this could reduce the waiting time on queue of next lot traveller. Operational time of man power could be known and controlled very well and this is very important to prevent any problematic scheduling such as set up time and the time a wire bond machine should start operating. Problem in scheduling will affect the flexibility in production operations, full utilization of men and machines and also the coordination between men and machines (Mugwindiri et al., 2013). These could be avoidable or minimized via MOST study.

\section{Conclusion}

In short, the hidden wastes which had been tolerated by OEE include unnecessary motion, lengthy and impropriate method of set up which further lead to higher time losses. OEE is said to be tolerating with these losses because it is impossible to track out the lean waste in term of motion or impropriate method by solely using OEE measures. This could be proven from the outcome that $73 \%$ of improvement in the setup process could merely lead to $2.22 \%$ of improvement in OEE measure. This highlights the lessened emphasis on the so-called hidden wastes like transportation and motion. As a conclusion, the study revealed that MOST study could minimize the unproductive movement which further reduce the downtime of wire bond machine. The aforementioned hidden wastes in OEE are revealed under the MOST study by considering the space of working area, distance between operator and work place as well as the nature of the job. It is recommendable to implement OEE along with other tools like MOST.

\section{Acknowledgement}

The author would like to express his acknowledgement to sponsor of a fund due to the financial support throughout the period at which research was carried out. The Fundamental Research Grant Scheme (FRGS) provided is coded FRGS_12015TK03FKP02F00279.

\section{Author's Contributions}

Puvanasvaran A. Perumal: Founder of the grant. Contributed to conceptualization, manuscript review and revision and research supervision.

Ito Teruaki: Contributed in development of mathematical modeling and simulation.

Teoh Yong Siang: Contributed to research design, literature review and manuscript preparation and revision.
Yoong Sai Sieng: Contributed to research design, literature review and manuscript preparation and revision.

\section{Ethics}

The author declares no cnflict of interest.

\section{References}

Abu Talib, B. and D. Daiyanni, 2010. Time motion study in determination of time standard in manpower process. Proceedings of the 3rd Engineering Conference on Advancement in Mechanical and Manufacturing for Sustainable Environment, Apr. 14-16, Kuching, Sarawak, Malaysia.

Adanna, I.W. and A. Shantharam, 2013. Improvement of Setup Time and Production Output with the use of Single Minute Exchange of Die Principles (SMED). Int. J. Eng. Res., 2: 274-277.

Benjamin, S.J., M.S. Marathamuthu and U. Murugaiah, 2015. The use of 5-WHYs technique to eliminate OEE's speed loss in a manufacturing firm. J. Quality Maintenance Eng., 21: 419-435. DOI: 10.1108/JQME-09-2013-0062

Kjell, Z. and H. Maynard, 2001. Maynard's Industrial Engineering Handbook. 1st Edn., McGraw-Hill Education, New York, ISBN-10: 0070411026, pp: 2688.

Kjell, B.Z., 2003. MOST Work Measurement Systems. 3rd Edn., CRC Press, ISBN-10: 0824709535, pp: 552.

Lee, J., E. Lapira, B. Bagheri and H.A. Kao, 2013. Recent advances and trends in predictive manufacturing systems in big data environment. Manufactur. Lett., 1: 38-41. DOI: 10.1016/j.mfglet.2013.09.005

Mugwindiri, K., W.R. Nyemba, I. Madanhire and R. Mushonga, 2013. The design of a production planning and control system for a food manufacturing company in a developing country, using simulation. Int. J. Applic. Innovat. Eng. Manage., 2: 116-15.

Puvanasvaran, A.P., Y.S. Teoh and C.C. Tay, 2014. Interrelationship between availability with planning factor and Mean Time Between Failures (MTBF) in Overall Equipment Effectiveness (OEE). J. Adv. Manufact. Technol., 6: 29-38.

Puvanasvaran, P., Y.S. Teoh and C.C. Tay, 2013. Consideration of demand rate in Overall Equipment Effetiveness (OEE) on equipment with constant process time. J. Indust. Eng. Manage., 6; 507-524. DOI: $10.3926 /$ jiem.537 
Samad, M.A., M.R. Hossain and S. Major, 2012. Analysis of performance by overall equipment effectiveness of the CNC cutting section of a shipyard. ARPN J. Sci. Technol., 2: 1091-1096.
Zeller, M., 2014. Convert operational data into maintenance savings. Proceedings of the IEEE Rural Electric Power Conference, May 18-21, IEEE Xplore Press. DOI: 10.1109/REPCon.2014.6842205

Appendix A: The basic MOST using the parameter sequence model on wire bond workstation

\begin{tabular}{|c|c|c|c|}
\hline Sub operation & Parameter and value & TMU & Min \\
\hline Walk 154 steps to wire bond process & $\mathrm{A}_{270} \mathrm{~B}_{0} \mathrm{G}_{0} \mathrm{~A}_{0} \mathrm{~B}_{0} \mathrm{P}_{0} \mathrm{~A}_{270}$ & 5400.00 & 3.2400 \\
\hline Get personal protective equipment and put it on & $\mathrm{A}_{16} \mathrm{~B}_{0} \mathrm{G}_{0} \mathrm{M}_{15} \mathrm{X}_{0} \mathrm{I}_{10} \mathrm{~A}_{0}$ & 410.00 & 0.2460 \\
\hline Walk 10 steps to the supervisor's area for a briefing & $\mathrm{A}_{16} \mathrm{~B}_{0} \mathrm{G}_{0} \mathrm{M}_{1} \mathrm{X}_{1800} \mathrm{I}_{0} \mathrm{~A}_{16}$ & 18330.00 & 10.9980 \\
\hline $\begin{array}{l}\text { Get machine hours sheet and walk } 10 \text { steps to } \\
\text { the information board }\end{array}$ & $\mathrm{A}_{16} \mathrm{~B}_{0} \mathrm{G}_{0} \mathrm{~A}_{0} \mathrm{~B}_{0} \mathrm{P}_{0} \mathrm{~A}_{16}$ & 320.00 & 0.1920 \\
\hline Update daily information based on machine hours & $\mathrm{A}_{3} \mathrm{~B}_{0} \mathrm{G}_{1} \mathrm{~A}_{3} \mathrm{~B}_{0} \mathrm{P}_{1} \mathrm{R}_{16} \mathrm{~A}_{1} \mathrm{~B}_{0} \mathrm{P}_{1} \mathrm{~A}_{6}$ & 320.00 & 0.1920 \\
\hline Get schedule and walk 10 steps to before cure area. & $\mathrm{A}_{16} \mathrm{~B}_{0} \mathrm{G}_{1} \mathrm{~A}_{3} \mathrm{~B}_{3} \mathrm{P}_{6} \mathrm{~T}_{1} \mathrm{~A}_{0} \mathrm{~B}_{0} \mathrm{P}_{6} \mathrm{~A}_{16}$ & 490.00 & 0.2940 \\
\hline Get a new lot and walk 7 steps to machine using the trolley & $\mathrm{A}_{16} \mathrm{~B}_{3} \mathrm{G}_{3} \mathrm{M}_{1} \mathrm{X}_{3} \mathrm{I}_{1}$ & 270.00 & 0.1620 \\
\hline Walk 5 steps into the machine & $\mathrm{A}_{10} \mathrm{~B}_{0} \mathrm{G}_{3} \mathrm{~A}_{0} \mathrm{~B}_{0} \mathrm{P}_{0} \mathrm{~A}_{0}$ & 130.00 & 0.0780 \\
\hline Transfer the lot into rack awaiting & $\mathrm{A}_{6} \mathrm{~B}_{0} \mathrm{G}_{3} \mathrm{~A}_{1} \mathrm{~B}_{0} \mathrm{P}_{6} \mathrm{~A}_{1}$ & 170.00 & 0.1020 \\
\hline Put the magazine in each section & $\mathrm{A}_{0} \mathrm{~B}_{0} \mathrm{G}_{0} \mathrm{~A}_{0} \mathrm{~B}_{0} \mathrm{P}_{3} \mathrm{~A}_{0}$ & 30.00 & 0.0180 \\
\hline Clip the lot traveler in wire bond machine & $\mathrm{A}_{1} \mathrm{~B}_{0} \mathrm{G}_{3} \mathrm{~A}_{0} \mathrm{~B}_{0} \mathrm{P}_{3} \mathrm{~A}_{6}$ & 130.00 & 0.0780 \\
\hline $\begin{array}{l}\text { Press the button, the machine starts to run the wire } \\
\text { bond machine }\end{array}$ & $\mathrm{A}_{3} \mathrm{~B}_{0} \mathrm{G}_{0} \mathrm{M}_{1} \mathrm{X}_{3} \mathrm{I}_{1} \mathrm{~A}_{1}$ & 90.00 & 0.0540 \\
\hline Checking the condition of gold wire (Machine running) & $\mathrm{A}_{1} \mathrm{~B}_{0} \mathrm{G}_{0} \mathrm{~A}_{1} \mathrm{~B}_{3} \mathrm{P}_{3} \mathrm{~T}_{1} \mathrm{~A}_{0} \mathrm{~B}_{0} \mathrm{P}_{0} \mathrm{~A}_{3}$ & 120.00 & 0.0720 \\
\hline Walk 4 steps into the wire bond machine & $\mathrm{A}_{6} \mathrm{~B}_{0} \mathrm{G}_{3} \mathrm{~A}_{0} \mathrm{~B}_{0} \mathrm{P}_{0} \mathrm{~A}_{6}$ & 150.00 & 0.0900 \\
\hline Arrange the output beside the machine & $\mathrm{A}_{3} \mathrm{~B}_{0} \mathrm{G}_{3} \mathrm{~A}_{3} \mathrm{~B}_{3} \mathrm{P}_{6} \mathrm{~A}_{3}$ & 210.00 & 0.1260 \\
\hline Check the condition of the machine & $\mathrm{A}_{6} \mathrm{~B}_{0} \mathrm{G}_{0} \mathrm{M}_{1} \mathrm{X}_{1} \mathrm{I}_{0} \mathrm{~A}_{0}$ & 80.00 & 0.0480 \\
\hline Adjust or set the position of gold wire & $\mathrm{A}_{1} \mathrm{~B}_{0} \mathrm{G}_{1} \mathrm{~A}_{1} \mathrm{~B}_{0} \mathrm{P}_{1} \mathrm{C}_{16} \mathrm{~A}_{1} \mathrm{~B}_{0} \mathrm{P}_{10}$ & 130.00 & 0.0780 \\
\hline Connect the 90 degree end of point to the middle part & $\mathrm{A}_{1} \mathrm{~B}_{0} \mathrm{G}_{0} \mathrm{M}_{1} \mathrm{X}_{0} \mathrm{I}_{0} \mathrm{~A}_{0}$ & 20.00 & 0.0120 \\
\hline Walk 17 steps to MES with bringing the lot & $\mathrm{A}_{32} \mathrm{~B}_{3} \mathrm{G}_{3} \mathrm{~A}_{0} \mathrm{~B}_{3} \mathrm{P}_{6} \mathrm{~A}_{6}$ & 470.00 & 0.2820 \\
\hline Get $5 \mathrm{~S}$ checklist from the storage compartment & $\mathrm{A}_{0} \mathrm{~B}_{0} \mathrm{G}_{0} \mathrm{~A}_{0} \mathrm{~B}_{0} \mathrm{P}_{0} \mathrm{R}_{10} \mathrm{~A}_{1} \mathrm{~B}_{0} \mathrm{P}_{1} \mathrm{~A}_{0}$ & 120.00 & 0.0720 \\
\hline $\begin{array}{l}\text { Walk } 10 \text { steps to wire area and check on all items regarded } \\
\text { on the checklist }\end{array}$ & $\mathrm{A}_{16} \mathrm{~B}_{0} \mathrm{G}_{0} \mathrm{~A}_{0} \mathrm{~B}_{0} \mathrm{P}_{0} \mathrm{R}_{10} \mathrm{~A}_{1} \mathrm{~B}_{0} \mathrm{P}_{1} \mathrm{~A}_{0}$ & 280.00 & 0.1608 \\
\hline $\begin{array}{l}\text { Walk } 4 \text { steps to wire bond machine in QA table and get a } \\
\text { checklist from upper holder }\end{array}$ & $\mathrm{A}_{6} \mathrm{~B}_{0} \mathrm{G}_{0} \mathrm{~A}_{0} \mathrm{~B}_{0} \mathrm{P}_{0} \mathrm{~T}_{1} \mathrm{~A}_{0} \mathrm{~B}_{0} \mathrm{P}_{0} \mathrm{~A}_{6}$ & 130.00 & 0.1980 \\
\hline Check and tick all items as per checklists & $\mathrm{A}_{0} \mathrm{~B}_{0} \mathrm{G}_{0} \mathrm{~A}_{0} \mathrm{~B}_{0} \mathrm{P}_{0} \mathrm{R}_{10} \mathrm{~A}_{1} \mathrm{~B}_{3} \mathrm{P}_{0} \mathrm{~A}_{0}$ & 140.00 & 0.0840 \\
\hline $\begin{array}{l}\text { Sign on checklist and place checklist back to } \\
\text { document holder }\end{array}$ & $\mathrm{A}_{1} \mathrm{~B}_{0} \mathrm{G}_{3} \mathrm{~A}_{0} \mathrm{~B}_{0} \mathrm{P}_{0} \mathrm{R}_{10} \mathrm{~A}_{0} \mathrm{~B}_{0} \mathrm{P}_{0} \mathrm{~A}_{0}$ & 140.00 & 0.0660 \\
\hline Total & 28350 & 17.01 & \\
\hline
\end{tabular}

